\title{
Estimates of the basic reproduction number for rubella using seroprevalence data and indicator-based approaches
}

Short title: Calculating basic reproduction number with seroprevalence and indicator data

$$
\text { Timos Papadopoulos }{ }^{1 *}, 4 \text {, Emilia Vynnycky } y^{1,2,3}
$$

* Corresponding author. Email: Timos.papadopoulos@phe.gov.uk. Postal address:

Statistics Modelling and Economics Department, Public Health England, 61 Colindale Avenue, Colindale, NW9 5HT, London, UK.

\section{Affiliations:}

1. Modelling and Economics Unit, Public Health England, 61 Colindale Avenue, Colindale, NW9 5HT, London, UK

2. TB Modelling Group and TB Centre, London School of Hygiene \& Tropical Medicine, London, UK.

3. Centre for Mathematical Modelling of Infectious Diseases, Faculty of Epidemiology and Population Health, London School of Hygiene \& Tropical Medicine, London, UK. 4. Institute of Sound and Vibration Research, University of Southampton, Southampton, UK

Short Title: Calculating basic reproduction number with seroprevalence and indicator data 


\section{Abstract}

The basic reproduction number $\left(R_{0}\right)$ of an infection determines the impact of its control. For many endemic infections, $R_{0}$ is often estimated from appropriate country-specific seroprevalence data. Studies sometimes pool estimates from the same region for settings lacking seroprevalence data, but the reliability of this approach is unclear. Plausibly, indicatorbased approaches could predict $R_{0}$ for such settings. We calculated $R_{0}$ for rubella for 98 settings and correlated its value against 66 demographic, economic, education, housing and health-related indicators. We also trained a random forest regression algorithm using these indicators as the input and $R_{0}$ as the output. We used the mean-square error to compare the performances of the random forest, simple linear regression and a regional averaging method in predicting $R_{0}$ using 4-fold cross validation. $R_{0}$ was $<5,5-10$ and $>10$ for 81,14 and 3 settings respectively, with no apparent regional differences and in the limited available data, it was usually lower for rural than urban areas. $R_{0}$ was most correlated with educational attainment, and household indicators for the Pearson and Spearman correlation coefficients respectively and with poverty-related indicators followed by the crude death rate considering the Maximum Information Coefficient, although the correlation for each was relatively weak (Pearson correlation coefficient: $0.4,95 \% \mathrm{Cl}:(0.24,0.48)$ for educational attainment). A random forest did not perform better in predicting $R_{0}$ than simple linear regression, depending on the subsets of training indicators and studies, and neither out-performed a regional averaging approach. $R_{0}$ for rubella is typically low and using indicators to estimate its value is not straightforward. A regional averaging approach may provide as reliable an estimate of $R_{0}$ for settings lacking seroprevalence data as one based on indicators. The findings may be relevant for other infections and studies estimating the disease burden and the impact of interventions for settings lacking seroprevalence data. 


\section{Author Summary}

The basic reproduction number $\left(R_{0}\right)$ of an infection, defined as the average number of secondary infectious people resulting from the introduction of an infectious person into a totally susceptible, determines how easily the infection can be controlled. For many established endemic infections, $R_{0}$ is estimated using data describing the presence of antibodies in a population obtained prior to the introduction of vaccination in that population (prevaccination seroprevalence data). For countries lacking such data the estimation is often done by pooling estimates from their geographical region. We estimated $R_{0}$ for rubella for 98 settings with existing prevaccination seroprevalence data and we investigated the effectiveness of using simple machine learning regression methods to predict $R_{0}$ from 66 demographic, economic, education, housing and health-related indicators in those same settings. Our results suggest that the indicator data and prediction methods under investigation do not perform better than regional pooling. We discuss possible ways of improving the prediction accuracy. Since research on predicting $R_{0}$ using socio-economic data is very scarce, our findings may also be relevant to estimating the disease burden and the impact of interventions in other pathogens. 


\section{Introduction}

The impact of an intervention against an infection greatly depends on the basic reproduction number $\left(R_{0}\right)$ of the associated pathogen, defined as the average number of secondary infectious people resulting from the introduction of a typical infectious person into a totally susceptible population[1]. For endemic vaccine-preventable infections, it is often estimated for a given setting from country-specific seroprevalence data collected before vaccination has been introduced[2], but it is unclear if estimates from one setting can be extrapolated to other countries. An understanding of how the basic reproduction number differs between settings is important for studies which try to either estimate the burden of an infectious disease or to predict the impact of interventions for settings without pre-existing seroprevalence data.

For settings without pre-vaccination seroprevalence data, studies sometimes base the prevaccination epidemiology and therefore $R_{0}$ on the regional average, calculated from the available data from all settings in the same geographical region[3-5]. It is also plausible that individual or combinations of socio-economic indicators could give insight into $R_{0}$ for a given setting. For example, the number of people that each person contacts might be expected to be correlated with factors such as the amount of crowding, which, in turn, is often correlated with other factors, such as poverty.

To our knowledge, the extent to which the regional average or particular indicators might predict what $R_{0}$ might be for a given setting has not been studied for any infection. The only related study is that of Santermans et al[6], which studied how differences in $R_{0}$ for varicella zoster for 9 European countries might be explained by differences in demographic, socio-economic and spatio-temporal indicators. The study found positive associations between $R_{0}$ and factors such as infant vaccination coverage for different vaccines and childcare attendance and negative associations with wealth inequality and poverty. As the study considered a small number of 
European countries and one infection, it is unclear whether the findings are generalisable either to other continents or to other infections.

In this study, we estimate the basic reproduction number for rubella for 98 settings from around the world and correlate its value against 66 demographic, economic, education, health and housing indicators. In addition, we compare the performance of simple linear regression and random forest approaches in predicting $R_{0}$ from these 66 indicators against $R_{0}$ estimated using a regional averaging approach.

\section{Results}

\section{Estimates of the basic reproduction number}

Fig 1 summarizes estimates of the basic reproduction number for each study. The basic reproduction number was less than 5 for over half of the settings, with the point estimate being below 5 for 81 settings and the upper 95\% confidence limit being below 5 for 62 settings respectively. The point estimate of the basic reproduction number was in the range 5-10 for 14 settings and exceeded 10 for just 3 settings, namely rural Chile, East Germany, and the Czech Republic before 1967, although the confidence intervals were very wide for each setting.

Fig 1: Estimates of the basic reproduction number for each of the studies. The blue circles reflect the values calculated from country-specific seroprevalence data, the red circles reflect the default $\boldsymbol{R}_{0}$ estimates and the vertical markers reflect $\boldsymbol{R}_{0}$ estimated from the regional point estimate of the force of infection. The bars reflect the $95 \%$ ranges of the estimates based on bootstrapping.

For most of the settings for which data were available for both urban and rural areas from the same year, the basic reproduction number was lower for urban than for rural areas, although the 
95\% confidence intervals sometimes overlapped. For urban and rural Peru before 1967, for example, it was 3.7 (95\% Cl: 3.3-4.4) and 2.2 (95\% Cl: 1.9-2.4) for respectively, and 6.5 (95\% Cl: 5.4-7.8) and $2.3(95 \% \mathrm{Cl} 2.1-4.0)$ for urban and rural Uruguay before 1967 respectively. Exceptions to this pattern included Chile from before 1967 for which the basic reproduction number was 3.9 (95\% Cl: 3.5-5.2) and 16.5 (95\% Cl: 12.8-25.2) for urban and rural areas respectively.

In general, the value for the basic reproduction number that would have been estimated for each setting using the default method was approximately 2.3-3.3 for countries in the African, American, Eastern Mediterranean, Western Pacific and South East Asian regions, and around 2.7-3.8 and 3.7-6.7 for countries in the Americas, Europe respectively. The 95\% range of the estimates based on the default approach, however, was very wide, with the upper limit of the $95 \%$ range reaching over 30 for several studies. The corresponding mean square error, calculated over all the studies, of $R_{0}$ for each setting based on the default approach compared to $R_{0}$ calculated using countryspecific seroprevalence data was approximately 7 , meaning that on average, estimates of $R_{0}$ of 4, for example, could be predicted to be as low as 1.5 or as high as 6.5. However, the error varied between regions (Table S5, Supplement), with the lowest MSE of around 1 being predicted for the African and Western Pacific regions, intermediate values of 5 predicted for the Eastern Mediterranean and South East Asian regions, and high values of 9 and 23 predicted for the Americas and Europe. The range of the MSE was also very wide and differed between regions, with a 95\% range of 1-16 and 13-695 from Africa and Europe respectively (Table S5, Supplement).

The same general patterns in the basic reproduction number were estimated for the alternative assumptions about contact between children and adults (Fig S2, Supplement), with $R_{0}$ being below 10 for most settings. For pessimistic assumptions about contact between children and adults, very high values for $R_{0}$ of above 20 were estimated for two settings, namely rural Chile 
and the Czech Republic before 1967. For both assumptions about contact, estimates of $R_{0}$ using the regional point estimate of the force of infection were usually smaller and led to a larger meansquare error than the default $R_{0}$ (Fig 1, Fig S2 and Table S5, Supplement).

\section{Correlation between $\boldsymbol{R}_{0}$ calculated using country-specific seroprevalence data and indicators}

In general, the indicators with which $R_{0}$, as estimated using country-specific seroprevalence data, was most correlated depended on the correlation coefficient and, when the correlation was calculated considering all 98 seroprevalence datasets, the correlation was generally weak (Table 1, Fig 2 and Table S6, Supplement). For the Pearson correlation coefficient, the greatest correlation was obtained between the basic reproduction number and the educational attainment among people aged $25+$ years $(0.495 \% \mathrm{Cl}: 0.24,0.48)$. For the Spearman correlation coefficient, three housing-related indicators had the highest correlation with the basic reproduction number, with the number of physicians per 1000 population having the next greatest correlation $(0.32,95 \%$ $\mathrm{Cl}: 0.22,0.37)$. Considering the MIC, the basic reproduction number had the greatest correlation with two poverty-related indicators, namely Poverty gap at $\$ 1.90$ a day $(0.37,95 \% \mathrm{Cl}: 0.21,0.34)$ and Poverty headcount ratio at $\$ 5.50$ a day $(0.36,95 \% \mathrm{Cl}: 0.22,0.37)$.

Fig 2: Indicators in each category with the largest Spearman correlation with $\boldsymbol{R}_{0}$ (correlation value and $\mathrm{Cl}$ in red font). The Pearson correlation regression line is plotted in red. 
Table 1: Summary of the top ten correlation coefficients and MIC for the association between the basic reproduction number and the indicators, obtai ned considering estimates of the basic reproduction number for all countries. The columns labelled " $\mathrm{CC}$ " hold the coefficient, with the $95 \%$ range obtained by bootstrapping; the column labelled "N" holds the number of data points used to calculate the coefficient.

\begin{tabular}{|c|c|c|c|c|c|c|c|c|c|}
\hline \multirow[b]{2}{*}{ Rank } & \multicolumn{3}{|l|}{ Pearson } & \multicolumn{3}{|l|}{ Spearman } & \multicolumn{3}{|l|}{ MIC } \\
\hline & Indicator & CC & $\mathbf{N}$ & Indicator & CC & $\mathbf{N}$ & Indicator & CC & $\mathbf{N}$ \\
\hline 1 & $\begin{array}{l}\text { Educational attainment, } \\
\text { at least completed upper } \\
\text { secondary, population } \\
25+, \text { total (\%) } \\
\text { (cumulative) }\end{array}$ & $\begin{array}{l}0.4 \\
(0.24 \\
0.48)\end{array}$ & 88 & $\begin{array}{l}\text { Number of households } 5 \\
\text { persons - Proportion over } \\
\text { All households }\end{array}$ & $\begin{array}{l}-0.45 \\
(-0.5 \\
-0.36)\end{array}$ & 56 & $\begin{array}{l}\text { Poverty gap at \$1.90 a } \\
\text { day (2011 PPP) (\%) }\end{array}$ & $\begin{array}{l}0.37 \\
(0.21 \\
0.34)\end{array}$ & 92 \\
\hline 2 & $\begin{array}{l}\text { Educational attainment, } \\
\text { at least completed upper } \\
\text { secondary, population } \\
25+\text {, female (\%) } \\
\text { (cumulative) }\end{array}$ & $\begin{array}{l}0.4 \\
(0.25 \\
0.47)\end{array}$ & 88 & $\begin{array}{l}\text { Number of households } 5 \\
\text { persons - Per capita }\end{array}$ & $\begin{array}{l}-0.41 \\
(-0.46 \\
-0.32)\end{array}$ & 56 & $\begin{array}{l}\text { Poverty headcount ratio } \\
\text { at } \$ 5.50 \text { a day ( } 2011 \text { PPP) } \\
\text { ( } \% \text { of population) }\end{array}$ & $\begin{array}{l}0.36 \\
(0.22 \\
0.37)\end{array}$ & 92 \\
\hline 3 & $\begin{array}{l}\text { Educational attainment, } \\
\text { at least completed upper } \\
\text { secondary, population } \\
25+, \text { male (\%) } \\
\text { (cumulative) }\end{array}$ & $\begin{array}{l}0.39 \\
(0.22 \\
0.47)\end{array}$ & 88 & $\begin{array}{l}\text { Number of households } 6 \\
\text { persons and over - Per } \\
\text { capita }\end{array}$ & $\begin{array}{l}-0.33 \\
(-0.41 \\
-0.22)\end{array}$ & 53 & $\begin{array}{l}\text { Crude death rate per } \\
1000 \text { population }\end{array}$ & $\begin{array}{l}0.35 \\
(0.2 \\
0.37)\end{array}$ & 98 \\
\hline 4 & $\begin{array}{l}\text { Number of households } 5 \\
\text { persons - Proportion over } \\
\text { All households }\end{array}$ & $\begin{array}{l}-0.34 \\
(-0.42 \\
-0.19)\end{array}$ & 56 & $\begin{array}{l}\text { Physicians (per 1,000 } \\
\text { people) }\end{array}$ & $\begin{array}{l}0.32 \\
(0.22 \\
0.37)\end{array}$ & 98 & $\begin{array}{l}\text { Life expectancy at birth } \\
\text { (both sexes) }\end{array}$ & $\begin{array}{l}0.34 \\
(0.2 \\
0.33)\end{array}$ & 98 \\
\hline
\end{tabular}


Table 1 (continued)

\begin{tabular}{|c|c|c|c|c|c|c|c|c|c|}
\hline Rank & Indicator & CC & $\mathbf{N}$ & Indicator & CC & $\mathbf{N}$ & Indicator & CC & $\mathbf{N}$ \\
\hline 5 & $\begin{array}{l}\text { Physicians (per 1,000 } \\
\text { people) }\end{array}$ & $\begin{array}{l}0.33 \\
(0.16 \\
0.41)\end{array}$ & 98 & $\begin{array}{l}\text { Prevalence of } \\
\text { underweight, weight for } \\
\text { age (\% of children under } \\
\text { 5) }\end{array}$ & $\begin{array}{l}-0.31 \\
(-0.34 \\
-0.21)\end{array}$ & 94 & $\begin{array}{l}\text { Poverty gap at } \$ 3.20 \text { a } \\
\text { day ( } 2011 \text { PPP) (\% of } \\
\text { population) }\end{array}$ & $\begin{array}{l}0.34 \\
(0.22 \\
0.36)\end{array}$ & 92 \\
\hline 6 & $\begin{array}{l}\text { Proportion of the } \\
\text { population aged } 65+\end{array}$ & $\begin{array}{l}0.32 \\
(0.2 \\
0.51)\end{array}$ & 98 & $\begin{array}{l}\text { Immunization, measles } \\
\text { (\% of children ages } 12-23 \\
\text { months) }\end{array}$ & $\begin{array}{l}0.3 \\
(0.22 \\
0.36)\end{array}$ & 98 & $\begin{array}{l}\text { Poverty headcount ratio } \\
\text { at } \$ 1.90 \text { a day ( } 2011 \text { PPP) } \\
\text { (\% of population) }\end{array}$ & $\begin{array}{l}0.34 \\
(0.22 \\
0.36)\end{array}$ & 92 \\
\hline 7 & $\begin{array}{l}\text { Number of households } 5 \\
\text { persons - Per capita }\end{array}$ & $\begin{array}{l}-0.28 \\
(-0.35 \\
-0.1)\end{array}$ & 56 & $\begin{array}{l}\text { Number of households } 6 \\
\text { persons and over - } \\
\text { Proportion over All } \\
\text { households }\end{array}$ & $\begin{array}{l}-0.29 \\
(-0.37 \\
-0.18)\end{array}$ & 53 & $\begin{array}{l}\text { Poverty gap at } \$ 5.50 \text { a } \\
\text { day ( } 2011 \text { PPP) ( } \% \text { of } \\
\text { population) }\end{array}$ & $\begin{array}{l}0.33 \\
(0.23 \\
0.37)\end{array}$ & 92 \\
\hline 8 & $\begin{array}{l}\text { Proportion of the } \\
\text { population aged 0-14 }\end{array}$ & $\begin{array}{l}-0.27 \\
(-0.39 \\
-0.14)\end{array}$ & 98 & $\begin{array}{l}\text { Health expenditure, total } \\
\text { (\% of GDP) }\end{array}$ & $\begin{array}{l}0.28 \\
(0.21 \\
0.35)\end{array}$ & 98 & $\begin{array}{l}\text { Poverty headcount ratio } \\
\text { at } \$ 3.20 \text { a day ( } 2011 \text { PPP) } \\
\text { (\% of population) }\end{array}$ & $\begin{array}{l}0.33 \\
(0.22 \\
0.37)\end{array}$ & 92 \\
\hline 9 & $\begin{array}{l}\text { Population living in slums } \\
\text { (\% of urban population) }\end{array}$ & $\begin{array}{l}-0.27 \\
(-0.32 \\
-0.13)\end{array}$ & 75 & $\begin{array}{l}\text { Urban population (\% of } \\
\text { total) }\end{array}$ & $\begin{array}{l}0.28 \\
(0.2 \\
0.34)\end{array}$ & 98 & $\begin{array}{l}\text { Proportion of the } \\
\text { population aged 0-4 }\end{array}$ & $\begin{array}{l}0.32 \\
(0.27 \\
0.38)\end{array}$ & 98 \\
\hline 10 & $\begin{array}{l}\text { Number of households } 6 \\
\text { persons and over - } \\
\text { Proportion over All } \\
\text { households }\end{array}$ & $\begin{array}{l}-0.26 \\
(-0.34 \\
-0.14)\end{array}$ & 53 & $\begin{array}{l}\text { Educational attainment, } \\
\text { at least completed upper } \\
\text { secondary, population } \\
25+, \text { total }(\%) \\
\text { (cumulative) }\end{array}$ & $\begin{array}{l}0.27 \\
(0.2 \\
0.35)\end{array}$ & 88 & $\begin{array}{l}\text { Physicians (per 1,000 } \\
\text { people) }\end{array}$ & $\begin{array}{l}0.31 \\
(0.25 \\
0.37)\end{array}$ & 98 \\
\hline
\end{tabular}


When the simple linear regression was repeated by region, economic indicators were the most correlated with the basic reproduction number in Africa (Table 2). For the Americas, healthrelated indicators, for example, the percentage of children who were aged under 6 months who were breast-feeding, the percentage of the population that was urban and several povertyrelated indicators were most correlated with the basic reproduction number (Table 2). For several indicators, the size of the correlation with $R_{0}$ was larger when they were calculated on a regional, compared to a global basis (Table 1, Table 2 and Fig 2). For the remaining regions, the small number of studies complicated the interpretation of the findings from linear regression (findings not shown). 
Table 2: Summary of the top five correlation coefficients and MIC for the association between the basic reproduction number and the indicators,

obtained considering estimates of the basic reproduction number just for countries in the African region or the Americas. The columns labelled "CC" hold the coefficient, with the $95 \%$ range obtained by bootstrapping; the column labelled " $N$ " holds the number of data points used to calculate the coefficient.

\begin{tabular}{|c|c|c|c|c|c|c|c|c|c|}
\hline \multirow[b]{2}{*}{ Rank } & \multicolumn{3}{|l|}{ Pearson } & \multicolumn{3}{|l|}{ Spearman } & \multicolumn{3}{|l|}{ MIC } \\
\hline & Indicator & CC & $\mathbf{N}$ & Indicator & CC & $\mathbf{N}$ & Indicator & CC & $\mathbf{N}$ \\
\hline \multicolumn{10}{|c|}{ African region } \\
\hline 1 & $\begin{array}{l}\text { Unemployment, total (\% } \\
\text { of total labor force) } \\
\text { (national estimate) }\end{array}$ & $\begin{array}{l}0.35 \\
(0.09 \\
0.48)\end{array}$ & 24 & $\begin{array}{l}\text { Poverty headcount ratio } \\
\text { at national poverty lines } \\
\text { (\% of population) }\end{array}$ & $\begin{array}{l}-0.4 \\
(-0.46 \\
-0.18)\end{array}$ & 24 & $\begin{array}{l}\text { Number of households } 3 \\
\text { persons - Proportion over } \\
\text { All households }\end{array}$ & $\begin{array}{l}1.0 \\
(0.19 \\
1.0)\end{array}$ & 6 \\
\hline 2 & $\begin{array}{l}\text { Poverty headcount ratio } \\
\text { at national poverty lines } \\
\text { (\% of population) }\end{array}$ & $\begin{array}{l}-0.33 \\
(-0.44 \\
-0.08)\end{array}$ & 24 & $\begin{array}{l}\text { Income share held by } \\
\text { highest } 10 \%\end{array}$ & $\begin{array}{l}0.38 \\
(0.17 \\
0.5)\end{array}$ & 24 & $\begin{array}{l}\text { Number of households } 4 \\
\text { persons - Proportion over } \\
\text { All households }\end{array}$ & $\begin{array}{l}1.0 \\
(0.19 \\
1.0)\end{array}$ & 6 \\
\hline 3 & $\begin{array}{l}\text { Income share held by } \\
\text { highest } 10 \%\end{array}$ & $\begin{array}{l}0.31 \\
(0.09 \\
0.54)\end{array}$ & 24 & $\begin{array}{l}\text { Health expenditure, total } \\
\text { (\% of GDP) }\end{array}$ & $\begin{array}{l}0.38 \\
(0.19 \\
0.52)\end{array}$ & 24 & $\begin{array}{l}\text { Immunization, measles } \\
\text { (\% of children ages } 12-23 \\
\text { months) }\end{array}$ & $\begin{array}{l}0.55 \\
(0.23 \\
0.65)\end{array}$ & 24 \\
\hline 4 & $\begin{array}{l}\text { Poverty gap at } \$ 1.90 \text { a } \\
\text { day (2011 PPP) (\%) }\end{array}$ & $\begin{array}{l}-0.3 \\
(-0.36 \\
-0.08)\end{array}$ & 24 & $\begin{array}{l}\text { Income share held by } \\
\text { highest } 20 \%\end{array}$ & $\begin{array}{l}0.33 \\
(0.15 \\
0.51)\end{array}$ & 24 & $\begin{array}{l}\text { Unemployment, total (\% } \\
\text { of total labor force) } \\
\text { (national estimate) }\end{array}$ & $\begin{array}{l}0.52 \\
(0.28 \\
0.59)\end{array}$ & 24 \\
\hline 5 & $\begin{array}{l}\text { Poverty gap at } \$ 3.20 \text { a } \\
\text { day ( } 2011 \text { PPP) (\% of } \\
\text { population) }\end{array}$ & $\begin{array}{l}-0.29 \\
(-0.34 \\
-0.06)\end{array}$ & 24 & $\begin{array}{l}\text { Educational attainment, } \\
\text { at least completed upper } \\
\text { secondary, population } \\
25+, \text { male }(\%) \\
\text { (cumulative) }\end{array}$ & $\begin{array}{l}-0.32 \\
(-0.45 \\
-0.06)\end{array}$ & 19 & $\begin{array}{l}\text { Physicians (per 1,000 } \\
\text { people) }\end{array}$ & $\begin{array}{l}0.49 \\
(0.27 \\
0.57)\end{array}$ & 24 \\
\hline
\end{tabular}


Table 2 (continued)

\begin{tabular}{|c|c|c|c|c|c|c|c|c|c|}
\hline \multirow[b]{2}{*}{ Rank } & \multicolumn{3}{|l|}{ Pearson } & \multicolumn{3}{|l|}{ Spearman } & \multicolumn{3}{|l|}{ MIC } \\
\hline & Indicator & CC & $\mathbf{N}$ & Indicator & CC & $\mathbf{N}$ & Indicator & CC & $\mathbf{N}$ \\
\hline \multicolumn{10}{|c|}{ Americas } \\
\hline 1 & $\begin{array}{l}\text { Exclusive breastfeeding } \\
\text { (\% of children under } 6 \\
\text { months) }\end{array}$ & $\begin{array}{l}0.45 \\
(0.3 \\
0.52)\end{array}$ & 23 & $\begin{array}{l}\text { Urban population (\% of } \\
\text { total) }\end{array}$ & $\begin{array}{l}0.61 \\
(0.53 \\
0.69)\end{array}$ & 26 & $\begin{array}{l}\text { Immunization, DPT (\% of } \\
\text { children ages } 12-23 \\
\text { months) }\end{array}$ & $\begin{array}{l}0.58 \\
(0.36 \\
0.63)\end{array}$ & 26 \\
\hline 2 & $\begin{array}{l}\text { Immunization, DPT (\% of } \\
\text { children ages } 12-23 \\
\text { months) }\end{array}$ & $\begin{array}{l}0.45 \\
(0.19 \\
0.51)\end{array}$ & 26 & $\begin{array}{l}\text { Exclusive breastfeeding } \\
\text { (\% of children under } 6 \\
\text { months) }\end{array}$ & $\begin{array}{l}0.59 \\
(0.52 \\
0.65)\end{array}$ & 23 & $\begin{array}{l}\text { Exclusive breastfeeding } \\
\text { (\% of children under } 6 \\
\text { months) }\end{array}$ & $\begin{array}{l}0.55 \\
(0.42 \\
0.6)\end{array}$ & 23 \\
\hline 3 & $\begin{array}{l}\text { Unemployment, total (\% } \\
\text { of total labor force) } \\
\text { (modeled ILO estimate) }\end{array}$ & $\begin{array}{l}-0.42 \\
(-0.5 \\
-0.28)\end{array}$ & 26 & $\begin{array}{l}\text { Prevalence of } \\
\text { underweight, weight for } \\
\text { age (\% of children under } \\
\text { 5) }\end{array}$ & $\begin{array}{l}-0.57 \\
(-0.67 \\
-0.47)\end{array}$ & 26 & $\begin{array}{l}\text { Poverty gap at \$3.20 a } \\
\text { day ( } 2011 \text { PPP) } \% \text { of } \\
\text { population) }\end{array}$ & $\begin{array}{l}0.53 \\
(0.41 \\
0.53)\end{array}$ & 26 \\
\hline 4 & $\begin{array}{l}\text { Educational attainment, } \\
\text { at least completed upper } \\
\text { secondary, population } \\
25+, \text { total (\%) } \\
\text { (cumulative) }\end{array}$ & $\begin{array}{l}0.42 \\
(0.21 \\
0.51)\end{array}$ & 24 & $\begin{array}{l}\text { Unemployment, total (\% } \\
\text { of total labor force) } \\
\text { (modeled ILO estimate) }\end{array}$ & $\begin{array}{l}-0.57 \\
(-0.62 \\
-0.48)\end{array}$ & 26 & $\begin{array}{l}\text { Poverty headcount ratio } \\
\text { at } \$ 3.20 \text { a day ( } 2011 \text { PPP) } \\
\text { (\% of population) }\end{array}$ & $\begin{array}{l}0.53 \\
(0.41 \\
0.53)\end{array}$ & 26 \\
\hline 5 & $\begin{array}{l}\text { Urban population (\% of } \\
\text { total) }\end{array}$ & $\begin{array}{l}0.42 \\
(0.28 \\
0.51)\end{array}$ & 26 & $\begin{array}{l}\text { Immunization, DPT (\% of } \\
\text { children ages } 12-23 \\
\text { months) }\end{array}$ & $\begin{array}{l}0.49 \\
(0.39 \\
0.59)\end{array}$ & 26 & $\begin{array}{l}\text { Adjusted net enrollment } \\
\text { rate, primary (\% of } \\
\text { primary school age } \\
\text { children) }\end{array}$ & $\begin{array}{l}0.48 \\
(0.32 \\
0.57)\end{array}$ & 25 \\
\hline
\end{tabular}




\section{Comparison between $\boldsymbol{R}_{0}$ predicted using simple linear regression and random forest} regression

Fig 3 compares the performance of simple linear regression, random forest and the default method for calculating $R_{0}$, as quantified by the MSE over the 4-fold cross-validation experiments, of the value predicted by these methods compared to that calculated using country-specific seroprevalence data. In general, the prediction error associated with using the default approach for calculating $R_{0}$ is comparable and in many instances slightly lower than the corresponding linear regression and random forest error, although the range of the error sometimes overlapped.

Fig 3: Mean value (blue and orange dots) and minimum-maximum value range (blue and orange line) of the MSE of the predicted $R_{0}$ over the 10 repetitions of the 4-fold crossvalidation experiment using the A. non-imputed and B. Imputed datasets. The blue color corresponds to the 66 linear regression results (one for each indicator) and the orange color to the 5 random forest results (one for each subset of indicators). The green dots indicate the average MSE for $\boldsymbol{R}_{0}$ as calculated using the default approach compared to that calculated using country-specific seroprevalence data.

When the missing indicators were not imputed (Fig 3 A), the error associated with predictions based on linear regression differed between indicators. For most indicators, the MSE values range from approximately 7.5 to 9 . The smallest error (MSE=2.73) was associated with a povertyrelated indicator ("Poverty gap at national poverty lines (\%)"). The errors associated with four indicators related to schooling, undernourishment, breastfeeding and living in slums were also considerably lower than most, with a MSE of 5.35-5.5. The errors associated with the indicators for the number of doctors' consultations, number of people per room and all the indicators related to number of households with various numbers of persons are higher than all the rest, ranging in values of 11 and upwards. The min-max range of the error is fairly narrow and the minimum MSE 
in badly performing indicators is generally higher than the maximum MSE of better performing indicators.

In the random forest non-imputed results, the lowest average MSE equals 6.88 for the random forest trained and tested using the 63 indicators that have up to 70 missing values and the highest average MSE is equal to 13.8 for the random forest trained and tested using the 50 indicators with up to 40 missing values.

In contrast, in the imputed data results (plotted in Fig 3 B) the MSE for all linear regression, random forest and default methods is similar at around the value of 8 .

As shown in Fig S3 (Supplement) much of the variation in the performance of the indicators in the simple linear regression and random forest analyses disappears once the two studies which have much higher values for $R_{0}$ than the other studies, namely, the Czech Republic and Chile (rural) ( $R_{0}=19.97$ and $R_{0}=16.53$ respectively) are omitted from the experiments. The individual prediction error of those two studies drives the overall MSE of the 4-fold cross validation experiment upwards. As can be seen in Table S7 in the supplementary material, the best performing indicator is the only one having a missing value for both those studies. In addition, the difference in the MSE between the default approach for predicted $R_{0}$ and simple linear regression and random forest methods reduces once these two studies are omitted from the experiments. Further details of the effect of the presence or absence of these two studies in the folds are provided in section S6 of the Supplement.

\section{Random forest parameter tuning}

In general, optimising the set of parameters used for the random forest algorithm for predicting $R_{0}$ led to a small reduction in average MSE, from 9.87 for the default set of parameters to 8.86 in the optimised case (these values correspond to the average of the MSE for the 10 repetitions 
plotted in Fig 4). In addition, the latter of those values was still higher than that associated with the default approach used for calculating $R_{0}$, for which the MSE was 6.97 (as plotted in Fig 3). As shown in Fig 4, the optimal value for the MSE obtained with the nested-optimisation method for the random forest algorithm did not vary considerably across the 10 repetitions, although the minimum to maximum range of the MSE across the 96 different sets of parameters varied. A more detailed exposition of the nested cross-validation optimisation results is given in section S7 of the Supplement. We note that the minimum end of the performance range (blue bars in Fig 4) is lower than the MSE error of the nested optimisation results in some of the 10 experiment repetitions. This is in accordance with previous theoretical and empirical comparison results between nested and non-nested optimisation methods[7].

Fig 4: Performance (as quantified by the MSE in each of the 10 splits to folds) of the default set of parameter values used in the random forest (yellow $\mathrm{x}$ ) compared to the optimal parameters for the random forest identified through nested optimisation (blue circle). Blue lines are the MSE minimum to maximum range for the 96 points of the parameters grid (hence this minimum is the optimal result of the non-nested optimization method).

\section{Discussion}

Our analyses found that the basic reproduction number for rubella is typically low and under 5 for many settings, which is consistent with the view that rubella is less infectious than other childhood immunizing infections, such as measles and mumps. We also found that in many cases, the basic reproduction number was lower for rural than areas but that the correlation between $R_{0}$ and indicators was not straightforward. In general, the performance of a regional averaging approach to estimate the basic reproduction number was often better than that using linear regression and random forest approaches. 
This is the first study to attempt to correlate the basic reproduction number for rubella in different time periods globally against different indicators. The only other related study to date, by Santermans et al considered varicella zoster and considered nine European settings[6]. The study found positive associations between $R_{0}$ and factors such as infant vaccination coverage for different vaccines and childcare attendance and negative associations with wealth inequality and poverty. As shown in our analyses, the correlation between indicators and $R_{0}$ for rubella is not straightforward, with the indicator with which $R_{0}$ had the greatest correlation depending both on the correlation statistic used and the region. In addition, the size of the correlation depended on the region considered, and was weaker when all study settings were considered than when the correlation was conducted on a regional basis. The size of the correlation in the latter case was comparable to that seen in Santermans et al[6].

The correlation between the basic reproduction number and several indicators was in the opposite direction from that expected. For example, in the simple linear regression analyses considering all countries, the basic reproduction number went down as the proportion of households which comprised 5 people increased and it increased as the number of physicians per 1000 population increased. This may have been due to other unknown factors confounding the observed relationship between $R_{0}$ and crowding indicators. It is also plausible that some outliers may have affected our results, but the extent to which this was the case is unclear. For example, considering Singapore, the estimated $R_{0}$ was low but the population density was much higher than in other settings.

Our finding that the basic reproduction number was typically higher in urban than in rural areas

(Fig 1) is consistent with the fact that the people in urban areas are more likely to contact others than people in rural areas. One of the exceptions to this was Chile from before 1967, for which $R_{0}$ in rural areas was several times greater than that in rural areas. An unexpectedly high estimate in rural areas might occur if, for example, the seroprevalence data had been collected shortly after 
an epidemic had occurred, resulting in unusually high levels of seroprevalence. Small differences in the $R_{0}$ between urban and rural areas may also occur if rural residents often visit urban areas, because of work or other reasons.

To our knowledge, our analyses are the first to assess the performances of regional averaging (default), simple linear regression and random forest approaches in predicting $R_{0}$. Although the latter two approaches are technically more sophisticated than the default approach it is interesting that, when all studies were considered, they were often out-performed by the default approach, based on regional averaging. However, we also note that the latter two approaches were sensitive to inclusion of two datasets with particularly high $R_{0}$ values and once they were excluded, the performance of the three approaches was similar. These findings suggest that for studies of the disease burden or the impact of interventions against rubella, indictor-based approaches are unlikely to improve upon using a regional averaging approach for settings lacking seroprevalence data.

There are several limitations of our analyses, which could have contributed to the indicator-based approaches under-performing when predicting $R_{0}$. For example, for simplicity, the value for the indicator used when correlating the basic reproduction number was taken from the year in which the study was conducted. In practice, the seroprevalence in the study year results from the exposure to rubella infection over the lifetime of the study population. In addition, when calculating the basic reproduction number, we just used one assumption for the contact between adults and children. Whilst that assumption is based on estimates from social contact studies from the past decade, it is plausible that for some of the settings in our study, such as those from many years ago, the amount of contact between people would have been different compared to that in recent years. In addition, due to the limitations of the seroprevalence data, which typically comprised convenience samples covering three or four age groups, we used a crude age stratification when calculating $R_{0}$, just considering two broad age groups. 
Our estimates of $R_{0}$ using the default approach involved taking the median of $R_{0}$ values as calculated using bootstrap-derived estimates of the force of infection from all studies in the same World Health Organization region. The performance of this approach may have been overestimated given that bootstrap-derived estimates used to calculate the median would have included those from each of the studies being used to evaluate the performance. In practice, the overestimate is likely to have been relatively small, given that at least 10 studies would have contributed to the bootstrap samples in each region. In this context, we note that in analyses of the global burden of CRS, which included the datasets using the one in this study, excluding a single seroprevalence dataset had little impact on estimates[4].

Several further refinements of both the default and indicator-based approaches for predicting $R_{0}$ are potentially feasible, although the effect on their performance is unclear. First, the default approach could be refined to use alternative methods for grouping the countries, such as those developed for Global Burden of Disease analyses, which are based on both epidemiological aspects and geographical location. However, application of this method for grouping countries is complicated by the fact that some groupings include only a few countries each of which may have no pre-vaccination seroprevalence data.

Second, the parameter optimisation experiment that we ran on the random forest regression algorithm was limited to only 6 parameters and to 2 or 3 values for each of those parameters. A search over a more extensive parameter grid (even though much more computationally intensive) could result in a reduction of the expected prediction error of the random forest algorithm. However, the small scale parameter optimisation conducted here suggests that the prediction results obtained with the random forest prediction method are close to the optimum and that not much further improvement can be expected by a finer or wider parameter grid search. 
Third, the effect of different methods for imputing missing values could be explored. As presented in the results, treating missing values with median value imputation has a significant effect on the prediction performance (Fig 3) and the effect of different methods of imputation on the prediction performance could be investigated.

Fourth, the prediction methods that we considered are unable to incorporate the uncertainty inherent in our data, which is present both in the indicator data that we use as input and in the estimated $R_{0}$ values that we use as the ground truth. Considering input data, the uncertainty can be quantified as the number of years of difference between the seroprevalence and the indicator data and this could also be modelled to fold in the case of missing data. In the case of the output the uncertainty can be quantified by the bootstrap-derived data distribution for different values of the contact parameter $k$. A Gaussian process methodology could be employed to incorporate those measures of uncertainty in the regression problem. The main advantage of such a method would be that it can provide a measure of uncertainty of the predicted results. For the prediction to be improved, it would be important for these measures of uncertainty to overcome one of the limitations of each of the prediction methods, namely that they are unable to correctly predict the very high values of $R_{0}$ for some settings (particularly for those in which $R_{0}>10$ ).

In conclusion, our analyses confirm the view that the basic reproduction number for rubella is low and that an approach based on regional averaging for settings lacking prevaccination seroprevalence is likely to perform as well as, if not better, than indicator-based approaches involving simple linear regression or random forest regression algorithms. It is unclear whether refinement of these methods could lead to an improvement in their performance. Whilst our analyses have focused on rubella, these findings are likely to be relevant for studies of the disease burden or the impact of interventions for other infections. 


\section{Methods}

\section{Data sources}

\section{Seroprevalence data}

The analyses use force of infection estimates (defined as the rate at which susceptible people are infected) for 98 rubella seroprevalence datasets that were identified in a systematic review and had been used previously in estimates of the global burden of Congenital Rubella Syndrome (CRS) and the impact of measles-rubella vaccination[4, 5]. The seroprevalence datasets are listed in Table S1 of the Supplement and were collected from 24, 26, 13, 13, 13 and 9 settings from the Africa, the Americas, Eastern Mediterranean, Europe, South East Asia and Western Pacific World Health Organization regions respectively before the introduction of rubella vaccination.

\section{Demography}

The age distribution considering single year age bands of each of the countries used in calculating the basic reproduction number was based on UN population data[8] for the year in which the study was conducted or the publication year, if the study year was unavailable. For instances in which the number of people aged 80 years and over is not stratified into single year age bands, we calculated this stratification using UN population data on the number of survivors by age.

\section{$\underline{\text { Indicators }}$}

For each of the 98 seroprevalence studies, we extracted 66 demographic, economic, education, health and housing indicators for the year in which the study was conducted, where possible. The indicators expand on 39 indicators used by Santermans et al in their study of $R_{0}$ for varicellazoster[6] and are summarized in Table S2 of the Supplement. For studies for which the study year was not known, the indicator was extracted for the year in which the data were published. If 
the value of the indicator for the actual study year was not available, the indicator was extracted for the year closest to the study year. Educational and employment were extracted from World Bank sources[9]. Economic and health-related indicators were extracted mainly from World Bank sources[9] but also from United Nations, International Monetary Fund, Organisation for Economic Co-operation and Development, World Health Organization and other sources[10-14]. Demographic data were extracted from United Nations population data and World Bank sources[8, 9]. Housing data were extracted from World Bank and United Nations Statistics Division sources[9, 15, 16]. Table S2 in the Supplement lists the data source for each indicator and it summarizes the completeness of data on the indicators for the studies and the number of studies for which values for the indicators in question were available within 5 years, 5-10 and >10 years of the study year. The number of indicator values available for each study are provided in Table S3. Values for the indicators were available for almost all of the studies, except for many of the housing-related indicators, which were not available for approximately $45 \%$ of the study settings. Values for all but one of the demographic indicators were available within 5 years of the study being conducted for all settings, and values for some of the economic indicators were only available more than 10 years after the study was conducted for $50 \%$ of the studies.

\section{Estimating the basic reproduction number}

For each of the 98 seroprevalence studies, estimates of the force of infection among those aged $<13$ and $\geq 13$ years, as published elsewhere[4, 5], were used to calculate the basic reproduction number, as the dominant eigenvalue of the Next Generation Matrix[1]. The forces of infection for each study are summarised in Fig 5. The matrix of Who Acquires Infection from Whom was assumed to have the following structure:

$$
\left(\begin{array}{cc}
\beta_{1} & k \beta_{2} \\
k \beta_{2} & \beta_{2}
\end{array}\right)
$$


Fig 5: Summary of the force of infection estimates used to calculate the basic reproduction number for each study in each region. The bars reflect the $95 \%$ ranges based on bootstrapping.

The effective contact rate differs between $<13$ and $\geq 13$ year olds, with its relative size between children and adults, compared to that between adults $(\mathrm{k})$, assumed to equal 0.7 , based on contact survey data[17]. In sensitivity analyses, we explored the effect of using pessimistic assumptions about mixing between younger and older people on estimates of the basic reproduction number, using a value of 0.3 for $\mathrm{k}$. The age distribution of the population used in calculating the basic reproduction number was based on UN population data[8] for the year in which the study was conducted or the publication year, if the study year was unavailable. The $95 \%$ range for the basic reproduction number for each study was calculated using 1000 bootstrap-derived samples for the force of infection, calculated as described in[4].

Previous studies have approximated the epidemiology of rubella in settings lacking seroprevalence by using a regionally averaging approach, using 1000 bootstrap-derived samples of the forces of infection compiled from all the studies from the same World Health Organization region[4,5]. To evaluate this approach, we calculated what the median $R_{0}$ in each of the 98 settings and its $95 \%$ range would have been estimated to be from these 1000 bootstrap-derived samples and we refer to this median $R_{0}$ as the "default $R_{0}$ " below. The error associated with the default $R_{0}$ and that calculated using seroprevalence data from the actual setting was quantified as the mean square error (MSE). The 95\% range of the MSE was calculated using 1000 bootstrap-derived estimates of the MSE computed from the corresponding $R_{0}$ estimates that were computed from 1000 bootstrap-derived force of infection. 
In sensitivity analyses, we also calculate what $R_{0}$ for a given setting would have been estimated to be using a point estimate of the age-dependent force for the region, which has previously been used to obtain an approximate estimate of the average CRS incidence for countries lacking seroprevalence data[5, 18]. This regional point estimate of the force of infection was taken as the value which led to the median burden of CRS out of the 1000 bootstraps in the absence of vaccination (see supplement in ref[5]).

\section{Measures of relation between indicators and $\boldsymbol{R}_{0}$ estimates}

The Pearson and Spearman correlation coefficients and the Maximum Information Coefficient (MIC) were calculated for the correlation between the basic reproduction number for each study and each of the 66 demographic, economic, education, health and housing indicators extracted for each study. The MIC has been used elsewhere in similar analyses for varicella zoster[6] and quantifies the correlation between two statistics when they may be non-linearly related[19]. The $95 \%$ range of the correlation coefficients were calculated using the 1000 bootstrap-derived values for the basic reproduction number. In the first instance, the correlation coefficients were calculated considering the basic reproduction numbers for all countries. In sensitivity analyses, the regression was repeated on a regional basis. In the results we present which rank the level of relation between the different indicators and $R_{0}$ from highest to lowest, we rank lowest all the indicators for which the $95 \% \mathrm{Cl}$ overlaps zero (i.e. the $2.5 \%$ and $97.5 \%$ percentiles of the bootstrap values are of opposite sign).

\section{Out-of-sample prediction}

\section{$\underline{\text { Overview }}$}

We explored whether the basic reproduction number for a given setting could be predicted using either simple linear regression on any of the 66 indicators or a Random Forest regression algorithm trained on different subsets of the indicators. We used 4-fold cross-validation[20] to 
score both approaches and explored the effect of imputation. Further details of the crossvalidation and imputation are provided below.

\section{$\underline{\text { Four-fold cross-validation }}$}

The 4-fold cross-validation process was similar for both the simple linear regression and random forest algorithms. A detailed description of the process ("experiment") is provided in section S3 of the Supplement and we summarize it briefly here.

First, the values for $R_{0}$ that had been estimated using country-specific seroprevalence data for the 98 studies, along with their indicators, were split into 4 partitions ("folds"). Next, for the case of simple linear regression and for a given indicator, the values in three of the folds were used as the training dataset to establish a relationship between the point estimate of $R_{0}$ that had been estimated using seroprevalence data, and that indicator. The values in the fourth fold were then used as the test dataset, whereby the value of the indicator for each study was used to predict what $R_{0}$ might be expected to be in that study using the linear regression model that had been estimated using the training dataset. We then calculated the mean square error (MSE) for the test dataset in these predicted $R_{0}$ values compared to those estimated using seroprevalence data. These steps were repeated using each fold in turn as the test dataset and the remaining three as the train dataset, and we computed the average MSE for the four folds. These steps were repeated for each of the indicators in turn.

The four-fold cross- validation was repeated using 10 randomly generated splits of the $98 R_{0}$ estimates to 4 folds, resulting in one value of the average MSE for each split and in the final stage of this process, we computed the average, minimum and maximum of those 10 average MSE values of the predicted $R_{0}$ compared to that calculated from study-specific seroprevalence data. 
We discarded splits to folds that had insufficient numbers of indicator values in each fold to train and test the linear regression algorithms (see further details below).

We used the steps and the same splits to folds as described above for estimating the performance of the random forest regression algorithm, except that subsets of indicators (rather than a single indicator at a time) are used train and test the random forest regression algorithm, as described below.

\section{Dealing with missing values in the indicator data}

Most of the 98 studies lacked values for some of the indicators (see Table S3 in the Supplement) and we explored the effect of both not imputing the missing values and of imputing them as follows.

\section{A. Non-imputation approach}

Not imputing the missing values has implications in the 4-fold cross-validation experiments. Considering the situation for simple linear regression, we note that the situation may arise where for a given indicator and a given split of the 98 studies to 4 folds, the training dataset has valid values for only one or none of the studies in it. In such cases it is not possible to fit a regression line. To address this, we generated a series of splits to folds and we kept the first 10 splits for which each indicator had at least one study with a valid value in each of the 4 folds (see section S3 of the Supplement for further details). This guarantees that for all folds and all indicators there are at least 3 studies with valid values in the training dataset which is sufficient for fitting a regression line and that there is at least one study with a valid value in the test dataset. With this arrangement, a study that has a valid value for a given indicator is used exactly once for testing and three times for training the linear regression model corresponding to that indicator in each of the 10 repetitions of the 4 -fold cross-validation experiment. 
For consistency, we used the same 10 splits to folds for the random forest 4-fold cross-validation experiments. Since random forest regression algorithms use all available indicators to train and predict the outcome of interest, rather than just one, as is the case for simple linear regression, the treatment of the missing data was different from that used for simple linear regression. Instead, we considered the following 5 different subsets of indicators and we ran a separate crossvalidation experiment for each subset:

- $\quad$ The 25 indicators that have no missing values at all, i.e. all 98 studies have values for those indicators.

- The 43 indicators that have up to 10 missing values. There are 69 studies which have values for each of those 43 indicators.

- $\quad$ The 46 indicators that have up to 20 missing values. There are 52 studies which have values for each of those 46 indicators.

- The 50 indicators that have up to 40 missing values. There are 32 studies which have values for each of those 50 indicators.

- $\quad$ The 63 indicators that have up to 70 missing values. There are 20 studies which have values for each of those 63 indicators.

We list the number of studies in the training and testing subsets for all 10 splits to 4 folds for both the linear regression and the random forest models in Table S4 in the Supplement.

\section{B. Imputation approach}

In the second approach we use imputation and we replaced all missing values (if any) of each indicator with the median value of the existing values among the 98 studies for that particular indicator. The imputation is applied once to the whole dataset prior to splitting to folds and all other parts of the cross-validation. With this approach there are no missing values in the imputed 
dataset and we were able to conduct all training and testing parts of the 4-fold cross-validation experiments as usual. For consistency purposes we used the same choice of 104 -fold splits of the non-imputed experiments that is described above.

Comparison of the linear regression, random forest $R_{0}$ predictions against those from the default $\underline{\text { method }}$

To assess whether the linear regression and random forest approaches performed better in predicting $R_{0}$ across the settings than using the default $R_{0}$ estimate, we computed the average, minimum and maximum values of MSE over the same test folds of the 10 cross-validation splits described above for the default $R_{0}$ estimate compared to $R_{0}$ estimated using country-specific seroprevalence data. The resulting MSE values were compared against those calculated considering the $R_{0}$ for the linear regression and random forest approaches. As described above, $R_{0}$ calculated using the default approach is taken as the median $R_{0}$ calculated from 1000 bootstrap-derived samples of the forces of infection compiled from all the studies from the same World Health Organization region.

\section{Random forest optimisation}

Unlike the fitting of a linear regression model, which is solely a function of the training dataset, the process of training a random forest prediction model is also a function of the choice of hyperparameters of the random forest. For the prediction performance comparison results that we described above we used the default parameter values of Python's scikit-learn toolbox. Further to that, we also present results of a separate small-scale parameter optimisation run. For that parameter optimisation experiment we used the same 10 cross-validation splits to 4 folds described above and the first indicators' subset listed above, i.e. the one comprising the 25 indicators that have no missing values. We present non-nested optimisation results as well as 
nested cross-validation optimisation results (see references[7, 21]). The former method amounts to simply selecting the parameter setup which achieves the lowest average MSE for a given split to folds. That method effectively violates the out-of-sample principle and can give over-optimistic estimates of the expected prediction performance in previously unseen test data. The latter case amounts to the results obtained when a separate inner-loop cross-validation experiment is run for each cross-validation fold and it is considered a more valid method to estimate the generalisation of the prediction performance in previously unseen test data.

\section{Software}

All computations were carried out in a reproducible manner using the corresponding methods and functions of Python's scikit-learn package[21]. The 10 splits to folds were obtained by use of the 'sklearn.model_selection.KFold' class by setting the 'random_state' parameter which corresponds to the seed of the pseudorandom generator to increasing integer values starting from 0. The values corresponding to folds that were used in the results are given in Table S4 in the Supplement. The linear regression and random forest prediction results were obtained with the methods of the 'sklearn.linear_model.LinearRegression'

and 'sklearn.ensemble.RandomForestRegressor' classes. The missing values imputation described in the 'Imputation approach' section was implemented using the 'sklearn.impute.Simplelmputer' class. For the random forest parameter tuning results we used a 6-parameter grid comprising 96 parameters' choices (details are given in section S5 of the supplementary material).

We note that due to the missing values in the dataset we could not use the higher-level methods of the scikit-learn package (e.g. 'sklearn.model_selection.cross_val_score') and that for all the results we had to write code that implements the complete cross-validation methodology. 
bioRxiv preprint doi: https://doi.org/10.1101/2021.05.12.443953; this version posted May 14,2021 . The copyright holder for this preprint (which was not certified by peer review) is the author/funder, who has granted bioRxiv a license to display the preprint in perpetuity. It is made available under aCC-BY-NC-ND 4.0 International license.

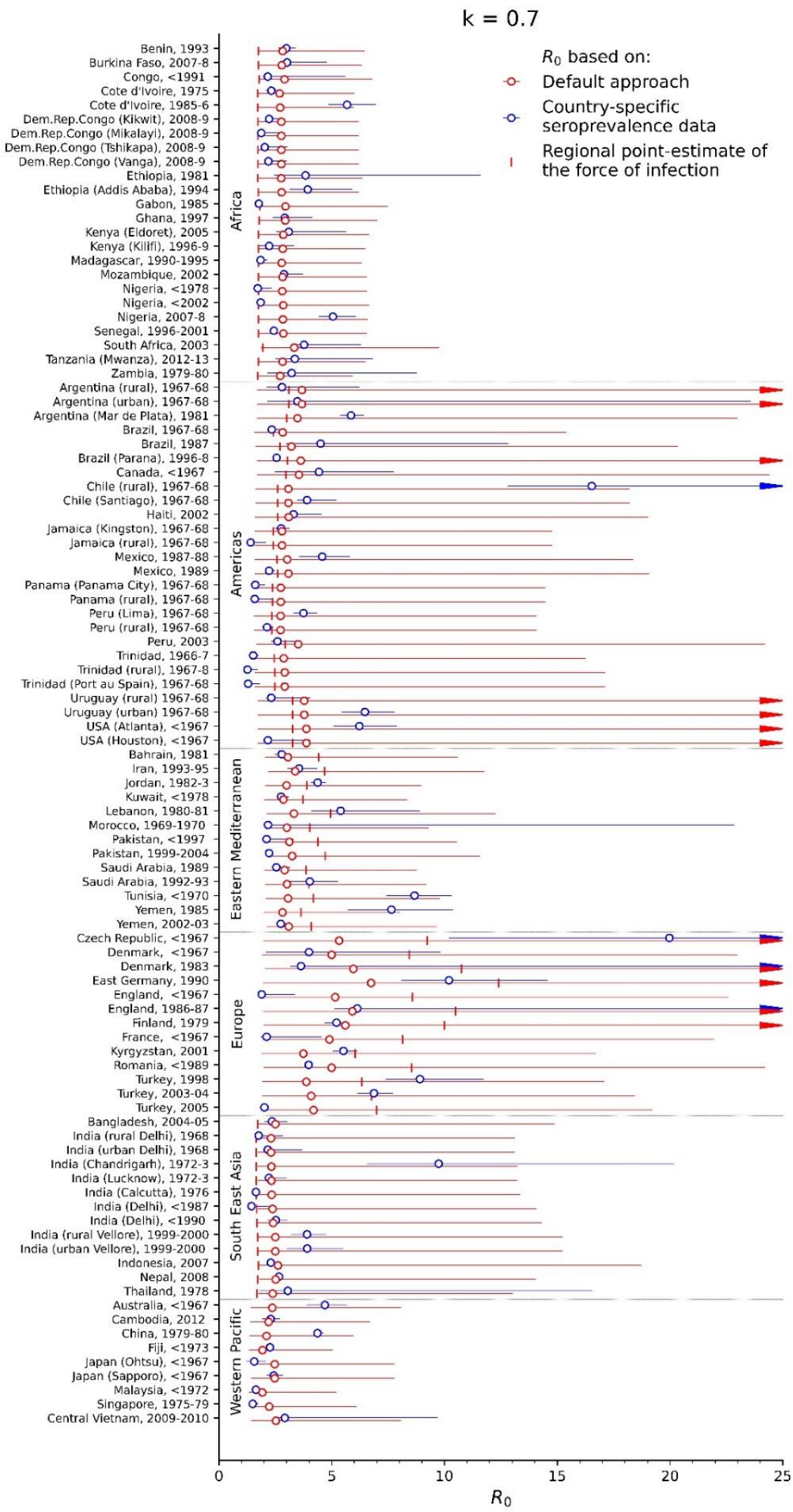

Fig 1 


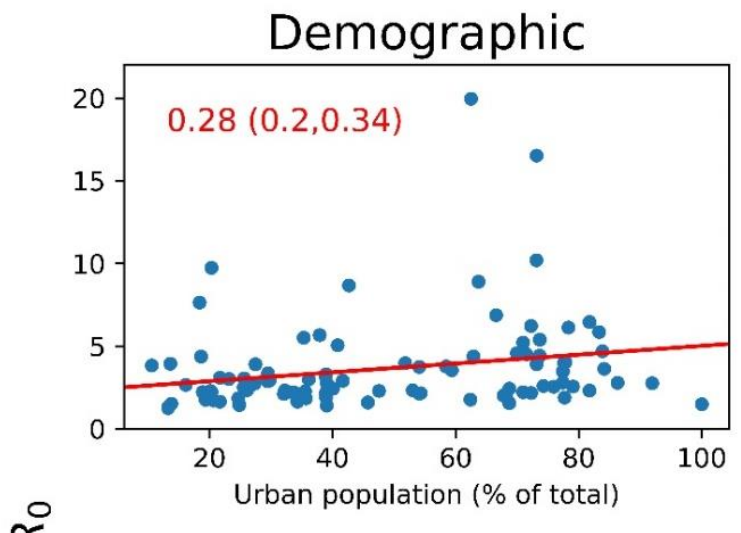

숭

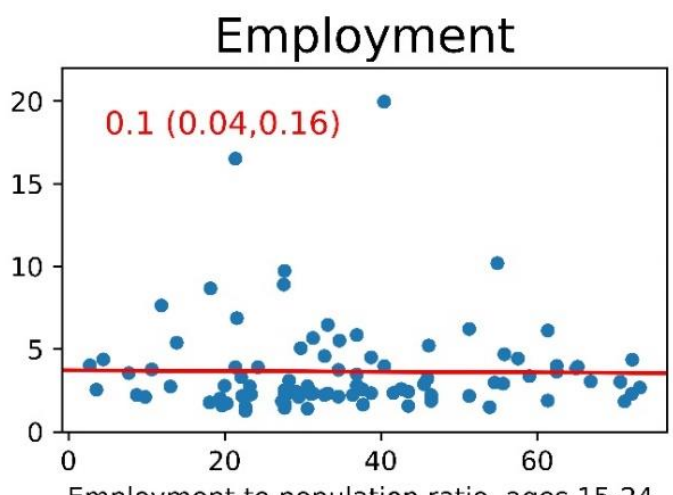

Employment to population ratio, ages 15-24, female (\%) (modeled ILO estimate)
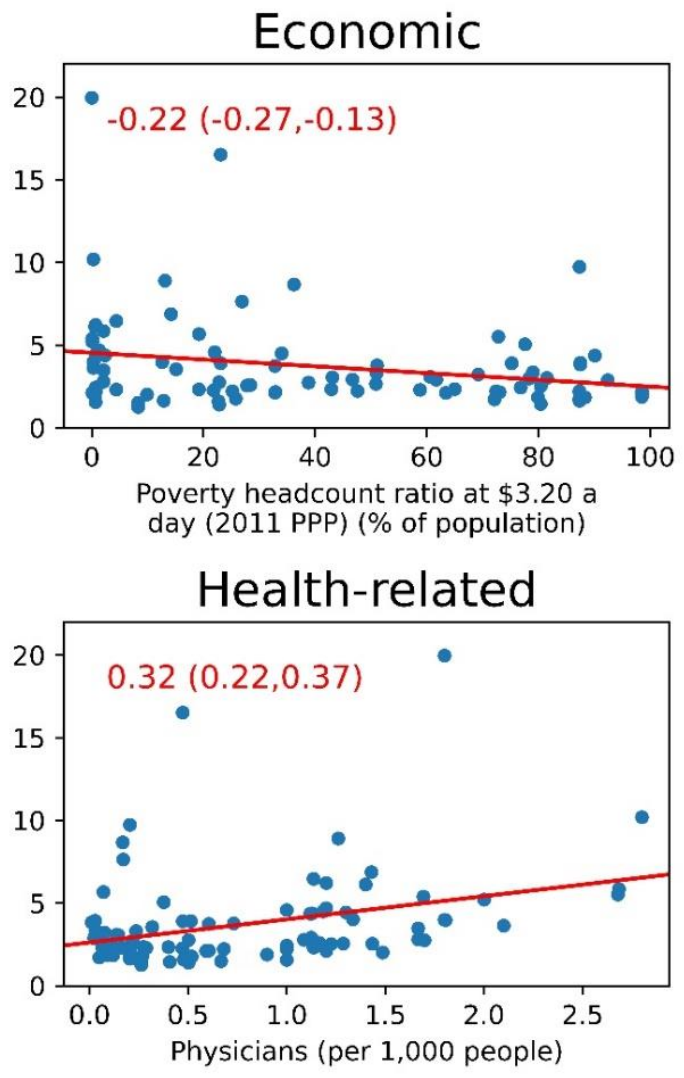

Fig 2
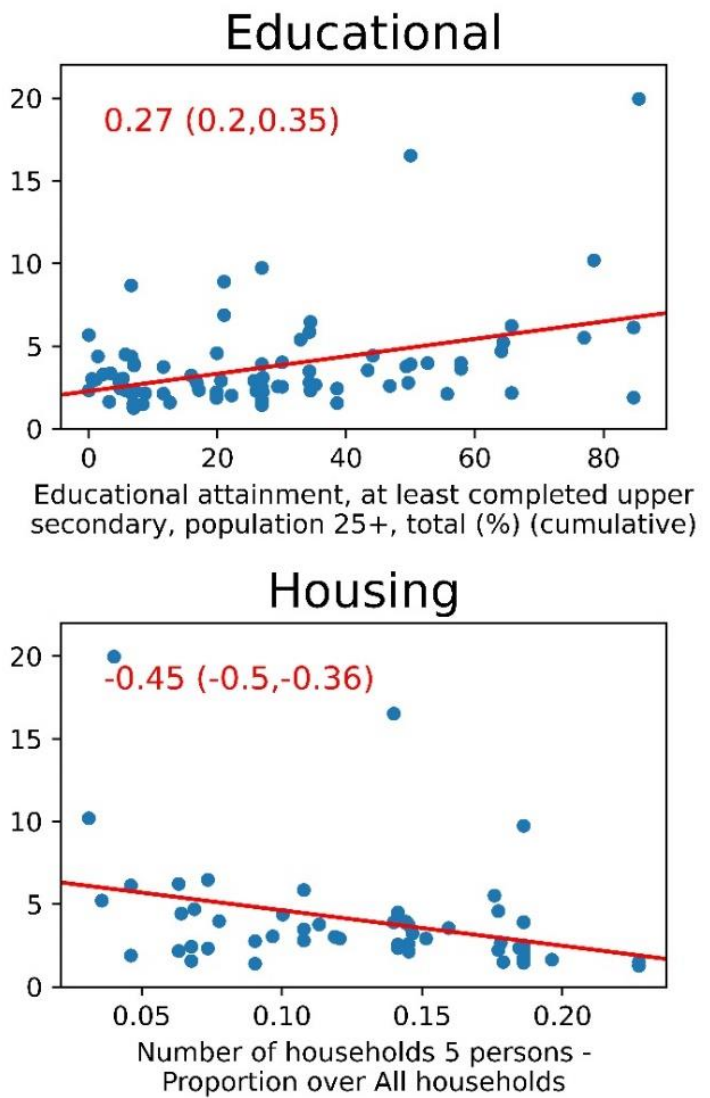
bioRxiv preprint doi: https://doi.org/10.1101/2021.05.12.443953; this version posted May 14, 2021. The copyright holder for this preprint (which was not certified by peer review) is the author/funder, who has granted bioRxiv a license to display the preprint in perpetuity. It is made available under aCC-BY-NC-ND 4.0 International license.

Proportion of the population aged $0-4$ Proportion of the population aged 0-14 Prop $65+$ Lifetime risk of maternal death Probability of dying before age 5 Crude death rate per 1000 population Life expectancy at birth (both sexes Total fertility rate (live births per woman) Mean age of child-bearing Population growth rate Population density Urban population (\% of total) ncome share held by highest $10 \%$ Income share held by highest $20 \%$ Income share held by lowest $10 \%$ Income share held by lowest $20 \%$ Poverty gap at $\$ 1.90$ a day Poverty gap at $\$ 3.20$ a day Poverty gap at $\$ 5.50$ a day Poverty gap at national poverty lines Poverty headcount at $\$ 1.90$ a day Poverty headcount at $\$ 3.20$ a day Poverty headcount at $\$ 5.50$ a day Poverty headcount at national poverty lines GDP per capita, PPP (constant 2011 international \$) GDP per capita, PPP (current international \$)

GDP per capita, current prices GDP per capita (1990 Int. GK\$) Adjusted net enrollment rate, primary
Educational attainment, upper secondary, female Educational attainment, upper secondary, male Educational attainment, upper secondary, total Unemployment, (modeled ILO estimate) Unemployment, (national estimate)

Employment/population, $15+$, female (ILO) Employment/population, $15+$, female(national)
Employment/population, $15-24$, female (ILO) Employment/population, 15-24, female (national) Low-birthweight babies (\% of births)

Prevalence of underweight (children under 5 ) Health expenditure total (\% of GDP)

Immunization, DPT (\% of children 12-23 months) Immunization, HepB3 (\% of one-year-old children) Immunization, measles ( $\%$ children $12-23$ months) Exclusive breastfeeding ( $\%$ of children $<6$ months) Physicians (per 1,000 people) Number of doctors' consultations HiB vaccination coverage HiB vaccination coverage
Average number of people per room Population living in slums ( $\%$ of urban population) Numof households All households - Per capita ( NumOf households 1 person - Per capita NumOf households 1 person - Proportion NumOf households 2 persons - Per capita NumOf households 2 persons - Proportion Numof households 3 persons - Per capita NumOf households 3 persons - Proportion NumOf households 4 persons - Per capita NumOf households 4 persons - Proportion NumOf households 5 persons - Per capita NumOf households 5 persons - Proportion Num of households $>6$ persons - Per capita NumOf households $>6$ persons - Proportion Total population in a household, both sexes RF - 25 indicators - no missing values $\mathrm{RF}$ - 43 indicators - up to 10 missing values $\mathrm{RF}-46$ indicators - up to 20 missing values RF - 50 indicators - up to 40 missing values RF - 63 indicators - up to 70 missing values -
Non-imputed

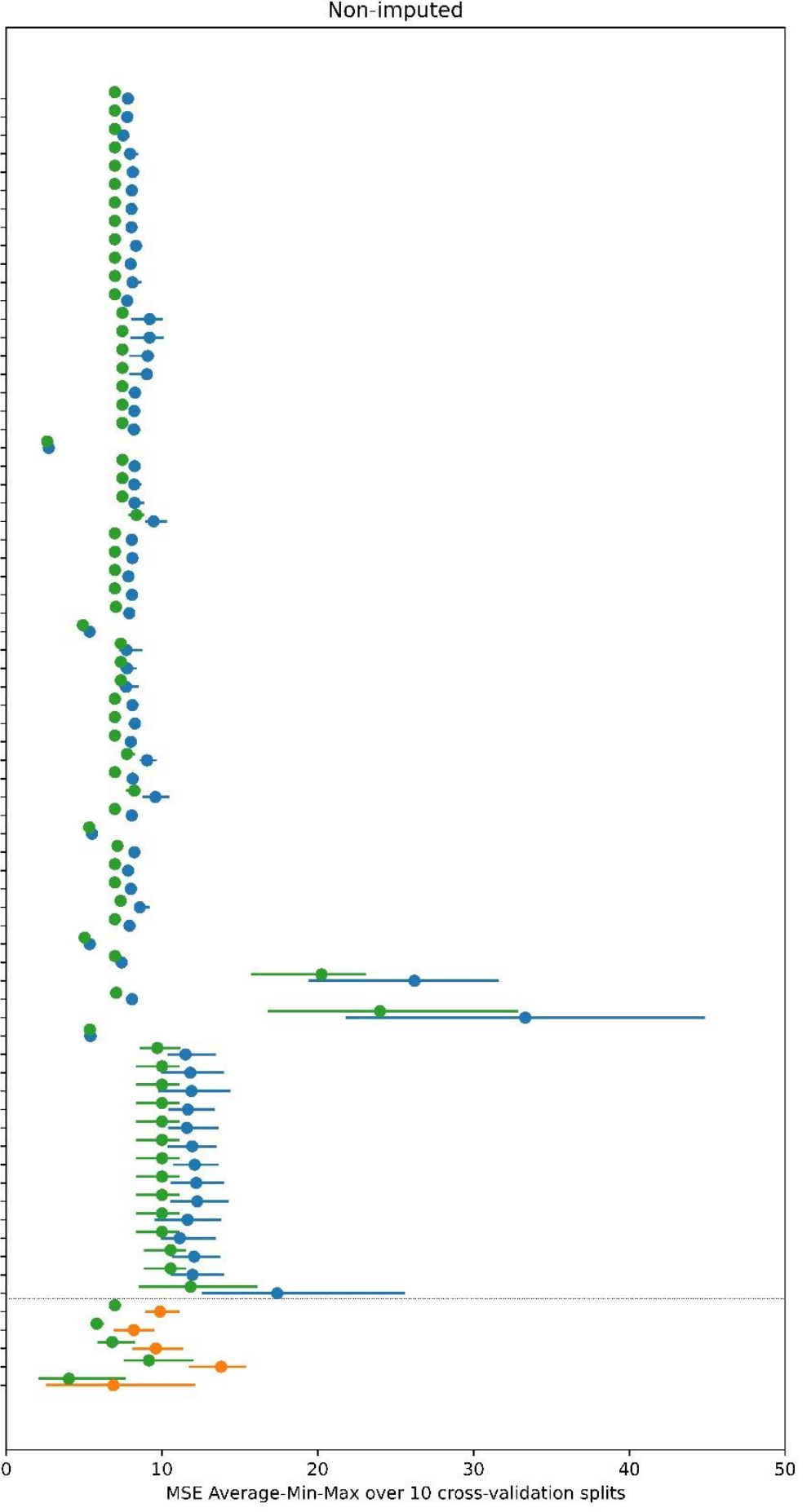

Fig $3 \mathrm{~A}$ 
bioRxiv preprint doi: https://doi.org/10.1101/2021.05.12.443953; this version posted May 14, 2021. The copyright holder for this preprint (which was not certified by peer review) is the author/funder, who has granted bioRxiv a license to display the preprint in perpetuity. It is made available under aCC-BY-NC-ND 4.0 International license.

Imputed

Proportion of the population aged $0-4$ Proportion of the population aged 0-14 portion of the population aged $65+$ Lifetime risk of maternal death Probability of dying before age 5 Crude death rate per 1000 population Life expectancy at birth (both sexes) Total fertility rate (live births per woman) Mean age of child-bearing Population growth rate Population density Urban population (\% of total) Income share held by highest 10\% Income share held by highest $20 \%$ Income share held by lowest 10\% Income share held by lowest $20 \%$ Poverty gap at $\$ 1.90$ a day Poverty gap at $\$ 3.20$ a day Poverty gap at $\$ 5.50$ a day

Poverty gap at national poverty lines Poverty headcount at $\$ 1.90$ a day Poverty headcount at $\$ 3.20$ a day Poverty headcount at $\$ 5.50$ a day Poverty headcount at national poverty lines GDP per capita, PPP (constant 2011 international \$) GDP per capita, PPP (current international \$)

GDP per capita, current prices GDP per capita (1990 Int. GK\$) Adjusted net enrollment rate, primary
Educational attainment, upper secondary, female Educational attainment, upper secondary, male Educational attainment, upper secondary, total Unemployment, (modeled ILO estimate) Unemployment, (national estimate)

Employment/population, $15+$, female (ILO)

Employment/population, 15+, female(national) Employment/population, 15-24, female (ILO) Employment/population, 15-24, female (national) Low-birthweight babies (\% of births)

Prevalence of underweight (children under 5 ) Health derweight (children under

Immunization, DPT (\% of children 12-23 months) Immunization, $\mathrm{HepB} 3$ (\% of one-year-old children) Immunization, measles (\% children 12-23 months) Exclusive breastfeedir Phy of children $<6$ months) Physicians (per 1,000 people) HiB vaccination coverage HiB vaccination coverage
Average number of people per room Population living in slums (\% of urban population) NumOf households All households - Per capita
Numbolation living in slums (\% of urban population Num NumOf households 1 person - Per capita NumOf households 1 person - Proportion NumOf households 2 persons - Per capita NumOf households 2 persons - Proportion Numof households 3 persons - Per capita Numof households 3 persons - Proportion NumOf households 4 persons - Per capita NumOf households 4 persons - Proportion NumOf households 5 persons - Per capita NumOf households 5 persons - Proportion NumOf households $>6$ persons - Per capita NumOf households $>6$ persons - Proportion Total population in a household, both sexes RF - 25 indicators - no missing values $\mathrm{RF}-43$ indicators - up to 10 missing values $\mathrm{RF}$ - 46 indicators - up to 20 missing values RF - 50 indicators - up to 40 missing values RF - 63 indicators - up to 70 missing values

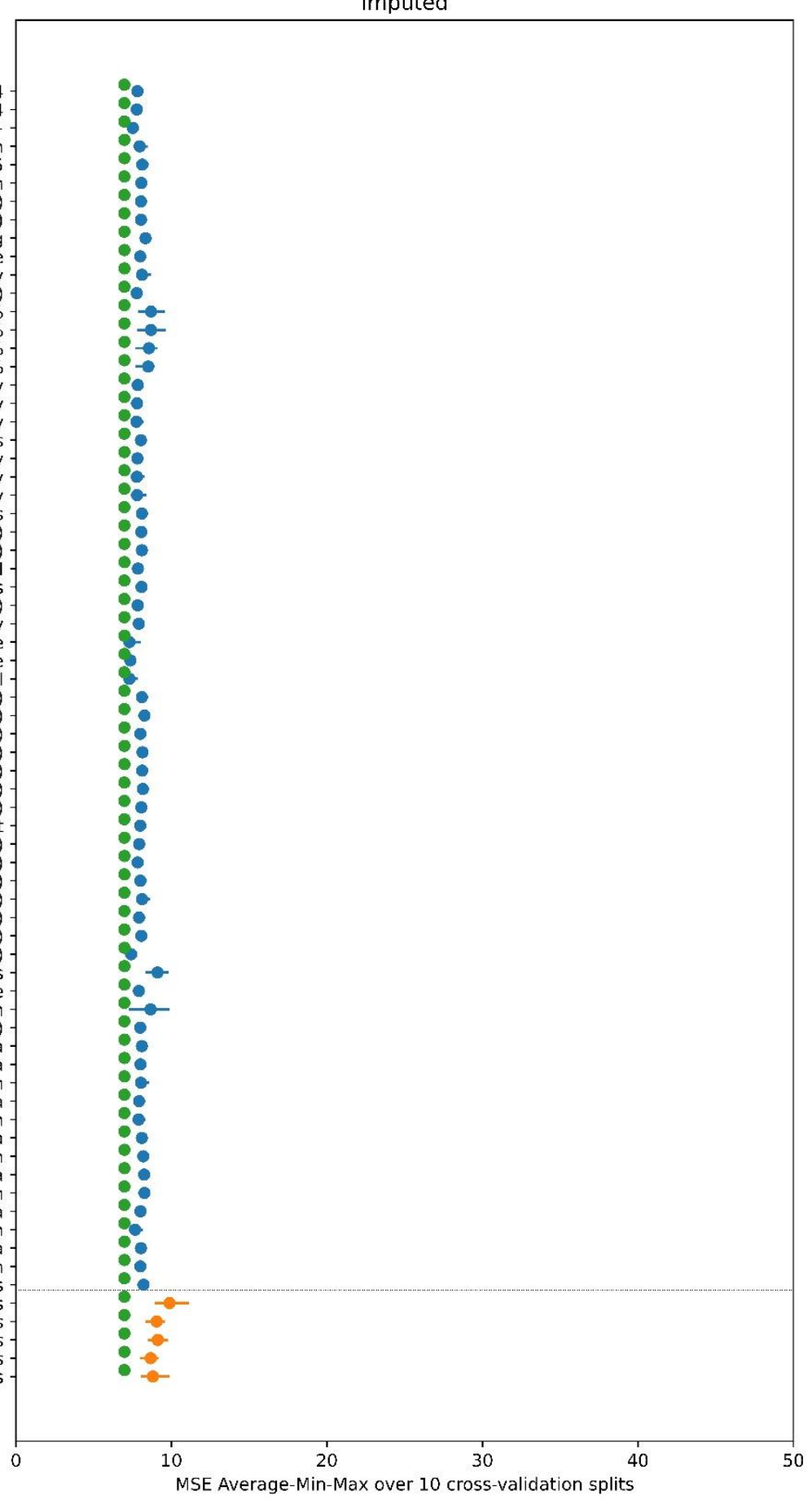

Fig 3 B 


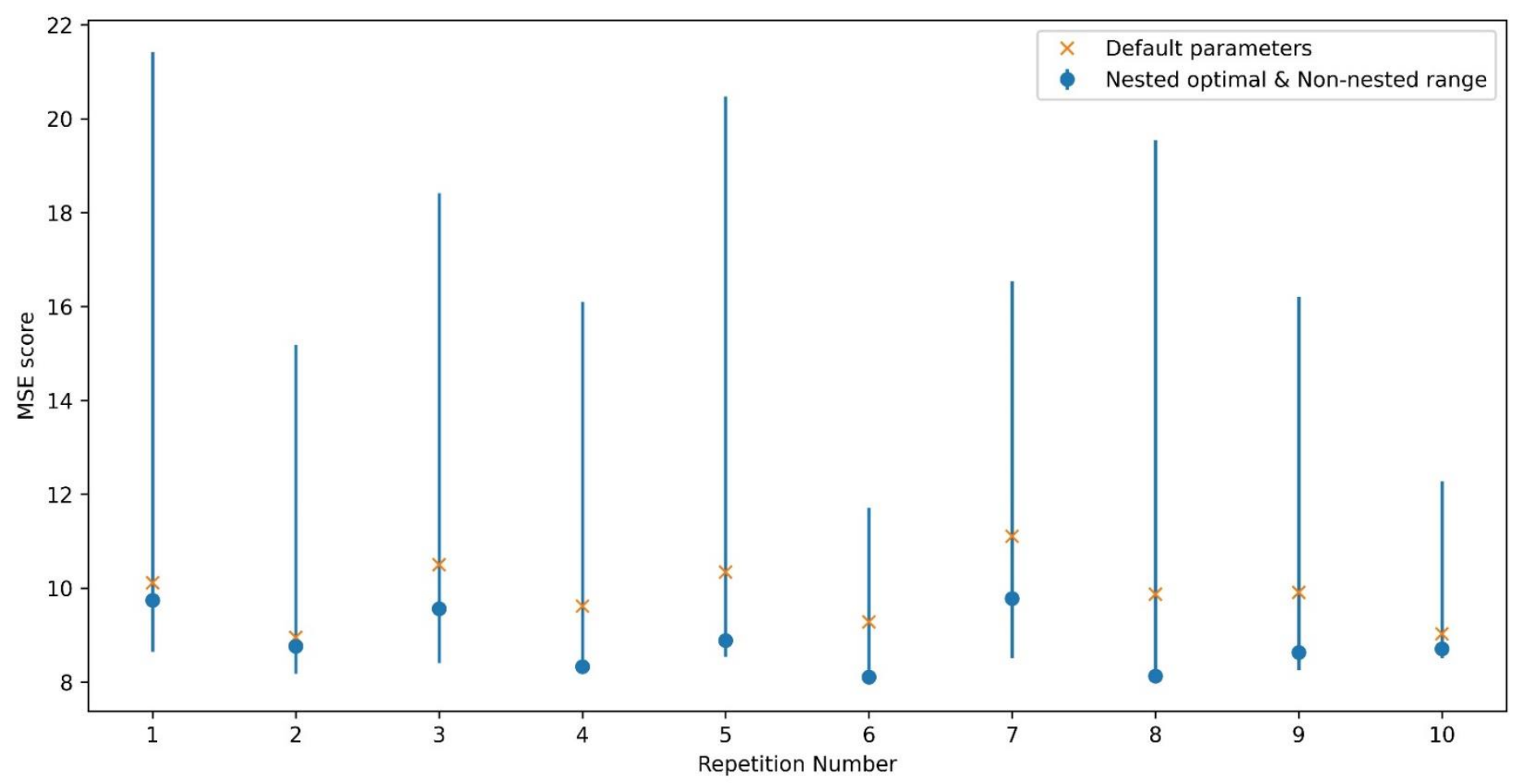

Fig 4 

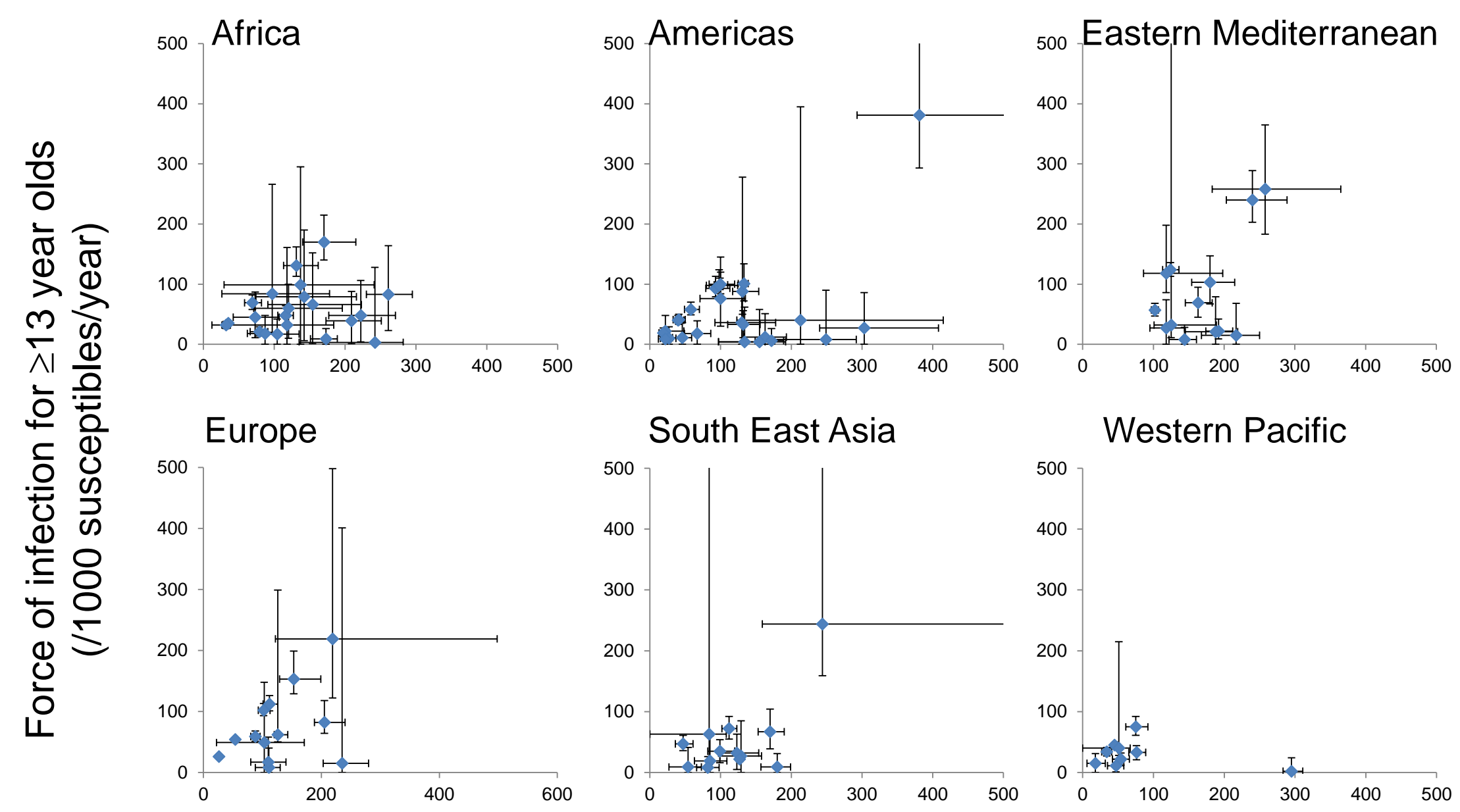

Force of infection for $<13$ year olds (/1000 susceptibles/year)

Fig 5 


\section{Funding}

This work was supported by funding from GAVI, the Vaccine Alliance, via the Vaccine Impact Modelling Consortium (VIMC, www.vaccineimpact.org). VIMC is jointly funded by Gavi, the Vaccine Alliance, and by the Bill Melinda Gates Foundation (BMGF grant number: OPP1157270).

The views expressed are those of the authors and not necessarily those of the Consortium or its funders. The funders were given the opportunity to review this paper prior to publication, but the final decision on the content of the publication was taken by the authors.

\section{References}

1. Diekmann O, Heesterbeek JA, Metz JA. On the definition and the computation of the basic reproduction ratio $\mathrm{RO}$ in models for infectious diseases in heterogeneous populations. J Math Biol. 1990;28(4):365-82. Epub 1990/01/01. PubMed PMID: 2117040.

2. Anderson RM, May RM. Infectious diseases of humans. Dynamics and control. Oxford: Oxford University Press; 1991.

3. Cutts FT, Vynnycky E. Modelling the incidence of congenital rubella syndrome in developing countries. Int J Epidemiol. 1999;28(6):1176-84. Epub 2000/02/08. PubMed PMID: 10661666.

4. Vynnycky E, Adams EJ, Cutts FT, Reef SE, Navar AM, Simons E, et al. Using Seroprevalence and Immunisation Coverage Data to Estimate the Global Burden of Congenital Rubella Syndrome, 19962010: A Systematic Review. PLoS One. 2016;11(3):e0149160. Epub 2016/03/11. doi:

10.1371/journal.pone.0149160 PONE-D-14-49494 [pii]. PubMed PMID: 26962867; PubMed Central PMCID: PMC4786291.

5. Vynnycky E, Papadopoulos T, Angelis K. The impact of Measles-Rubella vaccination on the morbidity and mortality from Congenital Rubella Syndrome in 92 countries. Hum Vaccin Immunother. 2019;15(2):309-16. Epub 2018/10/05. doi: 10.1080/21645515.2018.1532257. PubMed PMID: 30285537; PubMed Central PMCID: PMCPMC6422479.

6. Santermans E, Goeyvaerts N, Melegaro A, Edmunds WJ, Faes C, Aerts M, et al. The social contact hypothesis under the assumption of endemic equilibrium: Elucidating the transmission potential of VZV in Europe. Epidemics. 2015;11:14-23. Epub 2015/05/17. doi: 10.1016/j.epidem.2014.12.005. PubMed PMID: 25979278.

7. Cawley GC, Talbot NLC. On over-fitting in model selection and subsequent selection bias in performance evaluation. J Mach Learn Res. 2010;11:2079-107.

8. United Nations, Department of Economic and Social Affairs, Population Division, World Population Prospects. https://population.un.org/wpp/Download/Archive/Standard/2017. 
9. The World Bank Data Catalog, World Development Indicators.

https://datacatalog.worldbank.org/dataset/world-development-indicators/resource/08feba-8a62-11e6ae22-56b6b64900022017.

10. University of Groningen Growth and Development Centre, Maddison Database 2010.

https://www.rug.nl/ggdc/historicaldevelopment/maddison/data/md2010 vertical.xlsx.

11. IMF DataMapper.

https://www.imf.org/external/datamapper/PPPPC@WEO/OEMDC/ADVEC/WEOWORLD/.

12. Organisation for Economic Co-operation and Development, OECD.Stat, Health Care Utilisation: Consultations. https://stats.oecd.org/index.aspx?queryid=30161.

13. WHO Global Health Observatory data repository Hib (Hib3) Immunization coverage estimates by country. https://apps.who.int/gho/data/node.main.A829?lang=en.

14. UNITED NATIONS DEVELOPMENT PROGRAMME Human Development Reports Table 2. Human Development Index Trends, 1990-2015 http://hdr.undp.org/en/composite/trends2016.

15. United Nations, Department of Economic and Social Affairs, Statistics Division, Demographic Statistics Database, Population in households by type of household, age and sex. http://data.un.org/Data.aspx?d=POP\&f=tableCode:329.

16. United Nations, Department of Economic and Social Affairs, Statistics Division. Demographic Statistics Database, Households by age and sex of reference person and by size of household. http://data.un.org/Data.aspx?d=POP\&f=tableCode:50.

17. Mossong J, Hens N, Jit M, Beutels P, Auranen K, Mikolajczyk R, et al. Social contacts and mixing patterns relevant to the spread of infectious diseases. PLoS Med. 2008;5(3):e74. Epub 2008/03/28. doi: 07-PLME-RA-1231 [pii] 10.1371/journal.pmed.0050074. PubMed PMID: 18366252; PubMed Central PMCID: PMC2270306.

18. Lee LA, Franzel L, Atwell J, Datta SD, Friberg IK, Goldie SJ, et al. The estimated mortality impact of vaccinations forecast to be administered during 2011-2020 in 73 countries supported by the GAVI Alliance. Vaccine. 2013;31 Suppl 2:B61-72. Epub 2013/04/26. doi: S0264-410X(12)01628-3 [pii] 10.1016/j.vaccine.2012.11.035. PubMed PMID: 23598494.

19. Reshef DN, Reshef YA, Finucane HK, Grossman SR, McVean G, Turnbaugh PJ, et al. Detecting novel associations in large data sets. Science. 2011;334(6062):1518-24. Epub 2011/12/17. doi: 10.1126/science.1205438. PubMed PMID: 22174245; PubMed Central PMCID: PMCPMC3325791. 20. Hastie T, Tibshirani R, Friedmann J. The elements of statistical learning. Chapter 7. Princeton: Springer-Verlag; 2009.

21. Python The Scikit-learn package. https://scikit-learn.org/stable/. 